\title{
Effects of Climate Changes on the Diffusion of Infectious and Parasitic Disease: Environmental and Socio-Economic Impacts
}

\author{
Elvira Tarsitano ${ }^{1}$
}

\author{
${ }^{1}$ Sustainability Center, University of Bari Aldo Moro, Italy
}

\begin{abstract}
Scenarios on the impact of climate changes on health are evident: the era of disease caused by climate changes is arrived and the effects on health are very complex. Climate changes, environmental modifications in urban setting, the globalization, the intensification of trade exchanges and travels are contributing to modify the speed, beyond the dynamics, through which transmissible diseases may spread. The climate is changing now. The saying has to be: act now in order to prevent and to mitigate. The challenges that remain open therefore appear epochal and require deeper, faster and more ambitious responses and integrated solutions, to start the social and economic transformation necessary to achieve the 2030 Agenda Sustainable Development Goals (SDGs).
\end{abstract}

Keywords: Climatic Changes, Biodiversity, Infectious and Parasitic Diseases, Sustainable Development Goals

\section{Introduction}

\subsection{Introduce the Problem}

The succession of great emergencies, with the consequent inevitable interventions in the public health field, has led our country in this last twenty year period to pay significant attention to the emergencies bound with the diffusion of pathogenic agents correlated with climate changes and environmental interactions. The diffusion of pathologies often develop with transnational epidemic episodes that, beyond having morbidity and mortality associated, have generally serious social and economic consequences. In virtue of the emotional and media impact of these episodes, recognising promptly the epidemic emergencies, distinguishing them from potential "false alarms" is really important to face them efficiently. The interactions between environment-animals-humans, particularly in urban field, are often unpredictable because of climate changes (20). This makes necessary a deep knowledge of the different problems and a constant monitoring in time to prevent and, if necessary, intervene with a more adequate strategy in according with the CDC (Centers for Disease Control and Prevention) for One Health $(5 ; 11)$. The impact of infectious diseases on public health is periodically made worse by the emergence in epidemic form of infections hold up by new or well known pathogenic agents. On the basis of these emergencies there are high intrinsic evolutionary capabilities of microorganisms and their dynamics of interactions with man, animals and environment, that may lead to the creation and the rapid occupation of new ecological niches. The effects of climate changes on health are considerable. According to data released in early February by the European Union's Copernicus program
(Climate bulletins), the past January was the hottest ever recorded globally (8). In the last twenty years in Italy it is recorded variations in temperature with an increase of the maximum temperature of about $0.6^{\circ}$ in the North and of 0.8 in the South. Precipitation variations with a tendency in all the regions of an increase in the precipitation intensity and a decrease of the duration in terms of rain days. Sea level variation with the recording of an anomaly of the Mediterranean Sea, which does not increase in its level like oceans, it is observed, on one hand, an increase in the evaporation due to the global warming and, on the other hand, due to the reduction in precipitations, a decrease of water contribution of rivers and inland waters with the consequent increase in the salinity of the Mediterranean Sea. Soil quality variation at risk of desertification due to the climatic changes and the impact of human activities which exert a strong anthropic pressure on the territory, so that it is recorded a progressive biodiversity lost. The intensity of certain disasters in areas at risk results amplified and it is the consequence of the changes in the soil erosion due to the impacts of human settlings, with a consequent increase of the destructive strength of the event. Extreme events occur with more frequency and higher intensity. It is calculated that more than $2,6 \%$ are areas at risk of flooding and landslides. The future scenario as in the world, for Europe, Italy and regions which overlook on the Mediterranean Basin are not so rosy (21). According to the latest bulletin from the British Met Office, Europe, America, Africa, plus the northern areas, will suffer most from the increase in temperature in the coming years, and the projections, if confirmed, could seriously question the Earth's climate stability, making it ever more complicated to achieve the 
objectives present both in the Paris Agreement and in the 2030 Agenda. As for the next five years, the period 2020-2024, the global average temperature should fluctuate between $1.06{ }^{\circ} \mathrm{C}$ and $1.62{ }^{\circ} \mathrm{C}$ more than the average of the pre-industrial period (1850-1900), with a probability slightly below $10 \%$ to temporarily exceed $1.5{ }^{\circ} \mathrm{C}$ : the limit that the IPCC scientific community in the "special report" of 2018 recommends not to exceed, in order to avoid the most serious impacts on people and ecosystems by the climate change (3). Extreme events with falls on the productive, agricultural, urban and touristic systems. Direct impacts on health are due to the heat wave, flood, landslides and strong wind. Indirect impacts, on the contrary, concern the increase in allergic diseases, in transmissible diseases from vectors as described before. Increase water borne diseases to due the rise in inundations and damages of sewers with potable water and sewages contamination. Increases in temperature make record rises in salmonella infections, endemic disease in Italy (21). Displacement toward the North of the natural ecosystems with deep geographical changes, biodiversity loss and increase in desertification with repercussions on the whole economic systems and social tissue with an increase of the gap between the North and the South with problems of equity within a local population and with significant socio-economic impacts (9). The McKinsey Global Institute, an American think thank for expanding and deepening the discussion on global economic policy issues, published the report "Climate risk and response. Physical hazards and socioeconomic impacts" which shows that climate change is already having significant physical impacts at local level in regions around the world. The global socio-economic impacts of climate change will therefore be substantial: not only the environment will be affected, but also human beings and the activities related to them (26).

\subsection{Environmental interactions}

The numerous ecological niches present in urban environments encourage the increase in number of some animal species not always wanted by man: ideal temperature for the develop and growth, abundant food and water. It is determined a situation of and growth of the number of individual belonging to the same species, so that they represent a teasing for populations apart from determining the onset and diffusion of new pathologies. The urban ecosystems are characterized by microenvironments, by different subsets with environmental conditions which are very different among them, but spatially very close, in order to allow continuous and easy interchanges. In these microenvironments a very specialised and prevailing fauna develops in which the common equilibrium among the different species does not exist, relations are out of balanced, there is not much biodiversity and there are not the natural competitors which regulate the delicate species selection mechanisms (15). Once settled in a city, some animal species spread rapidly and, undisturbed, colonize other niches and create a series of dangerous interconnections and problems which involve different interests and competences. As consequence of the anthropic flu on global and territorial cycles and on single ecosystems, becomes essential the development of certain subjects such as the urban ecology, the urban hygiene and the integrated pest management in order to understand the whole phenomena which occur in the urban ecosystems, aiming specifically at steering the management choices towards protective measures for the public health and environment (18). Besides, this would allow to contrast the tendency to build life environments which consider only man's exigencies, forgetting that, next to the human population, there is a wide animal population brought by man (pets) and one that invades niches created artificially by him (sinanthropic animals: mosquitoes, cockroaches, mice, pigeons...) (15).

\subsection{Effects of climate changes on the spread of pathogens}

For instance, since a lot of years, it is known the role played by sinanthropic animals as potential means of zoonosis from howlers. The coexistence man-animal has taken, specifically in the urban environment, a significant importance both for social and economic implications and those hygienic and medical ones. The urbanization of areas originally rural, has led to modifications in life styles and culture population while a greater zoophilous sensitivity has allowed the social and affective recognition of the animal kept for company. In a survey it is estimated that in Italy 6,8 thousands of dogs and 8,5 thousands of cats live in families; to dogs and cats it is necessary to add other small animas such as rodents, fish in aquarium and birds. In this context the exigency of greater knowledges from a hygienic and medical point of view arises, aiming at controlling the situation $(20,21)$. As for the mycosis, a great number of species of fungi capable of determining infections in men and in animals are known, but among them only few are really transmissible from the animal to man. Most of the pathogenic howlers, indeed, are not parasites and live as saprophyte, very often as esa saprophyte and only in particular conditions, bound with the parasite, but above all, with the host, may carry on their potential pathogenesis (4). In a urban environment three types of mycotic diseases are recognized: Zoonosis with a urban cycle; Zoonisis associated with the animalization of urban areas; Zoonosis which may be transmitted from the rural environment to the urban one. The increase of zoophilic dermatophytosis like human dermatophyte agents, allows to state that animals play an important role in the transmission of disease to man. The isolation of aetiological agents in dermatophyte infections in animals, and specifically, in those of affection, is necessary, however, both for a diagnostic purpose and to deepen knowledges on epidemiology. The wide polymorphism of lesions, due to the attendant presence of other pathogen agents, may render difficult the 
mycotic diagnosis on the basis of the clinic dates and besides, it must not be undervalued the fact that the animal may behave as an asymptomatic carrier, taking the primary role in the diffusion of infection $(4,21)$. It derives that in a city, beyond the "conventional" planning, like those territorial and urban ones for a correct management of waste, water, air, traffic and all commercial, craft and tertiary activities, is important a planning which considers the presence of pets (dogs, cats and others) and synanthropic animal (insects, mice, birds and others) (20). The competent authorities should investigate on the medical risks bound with the presence of pets and synanthropic animals in the urban environment, predisposing epidemiologic targeted surveys. In addition, considering that these animals are potential vectors or reservoir of different infectious agents, have become also the target through which it is possible to control and make an adequate prevention of diseases transmitted by them (15). Modifications of ecosystems, man's contact with those environments not transformed to meet human needs, the rapid evolution of the intensive farming techniques of animals and the increase of the of food and animal transport have changed the relationship between animals and men and have favoured the appearance of new zoonoses (emerging) or have changed the epidemiological scenarios already existing (remerging). Transmissible diseases from animals to man (zoonosis) represent an important aspect of the public health, with remarkable social and economic consequences. More than $60 \%$, of all the pathogenic agents in men, have animal reservoirs and it is estimated that about the $75 \%$ of new and emerging diseases have animal origin. Historically, zoonoses constitute a serious problem of Public Health, subjected to a continuous evolution of epidemiological scenarios. In the last years these evolutionary processes have underwent a sharp acceleration due to a complex series of biological, environmental and economic factors. An infection is defined emerging when it appears in a population which it was not present in, or when its incidence and/or its geographic area of diffusion raise rapidly. An important infection rate, considered today emerging or remerging, is made up by zoonosis (transmissible diseases from animals to men), and the capacity of a microorganism to make the so called "cross the species barrier", that is to say the passage from a host animal to another and/or to man, represents one of the factors which contribute most to the emergence of a pathogen (21). Factors that have favoured in the last ten years the enlargement of the spectrum and the diffusion of pathogenic agents and zoonosis include environmental and climate changes such as the deforestation and the increase in temperature and in trade exchanges; the new intensive farming techniques; the enlargement of species of animal kept for company; the increase in recreational activities in wooded environments. What is considered really important, is the integration of diagnosis, control and monitor activities in the veterinary field with those made in the medical field for the diagnosis and research on the most important pathogenic agents, responsible for the epidemic events which have characterized and characterize the public health scenario in the last years. The bird flu, the SARS Coronavirus, transmissible viruses from arthropod vectors, such as the West Nile encephalitis virus, the Chikunguya, Zika Virus, dengue and other arbovirus (21). Just think about what's going on in the world, in Europe and also in Italy with the spread of the new coronavirus $\mathrm{nCoV}-2019$. The fight against coronavirus has mobilized the world. Isolation of entire cities, blocking of air travel, diffusion of scanners and tests, immediate search for a vaccine: under the guidance of the World Health Organization and with strong responses from national states too (27).

\subsection{The research on the evolutionary dynamics of pathogenic agents}

In Italy, at regional and national level, the research on the evolutionary dynamics of pathogenic agents is at the moment splitted, with divisions working on a lot of aspects (organisms, host and cycles of transmission), but the greatest barrier is that between public health and vets. These barriers have prevented an integrated approach to the research and hindered progresses in the prevention and control of diseases of animal origin (21). For this purpose, it is necessary to use adequate diagnostic instruments and monitoring systems based on an integration activity among veterinary and medical, biological, environmental sectors, in order to favour a continuous and rapid exchange of information about the superiority of different agents and about the characteristics of strains circulating in the different species of animal reservoirs and in the human population in according with one health (16). The colonization phenomenon of city by sinanthropic animals, is one of the remarkable health problem both in the international field and in the national one. In urban setting favourable environmental conditions, which have led to a demographic explosion of animal population and pathologies transmitted by them, established. The increase in average seasonal temperatures, recorded at a global level, and the numerous situations of environmental deterioration are among the most important causes of the increase of cases of infections transmitted by arthropods to men and animals (6). In particular, the diffusion of the "tiger mosquito" (Aedes Albopictus) and other annoying insects is a problem always more present in our cities as potential cause of new medical emergencies $(6,21)$. The risk of diffusion of infectious and parasitic diseases in Europe, included zoonoses, as consequences of the global climate change, has led to the development of a scientific method to identify pathologies that could be correlated to climatic changes and the risks associated to them have been classified. In particular, a predictive system of climate global changes, with its relative consequences for the West Europe, has been valued. The countries in the Mediterranean Sea might face high temperatures 
characterized by insufficient rain precipitations which would cause a change in local vegetation and ecosystems. Those diseases whose evolution might be influenced by climate changes have been found and the epidemiology and the modalities of transmission have been studied (6). The global heating may influence in a different way disease transmitted through the air, water and the anthropods going to affect their ecology and diffusion. For these diseases the possible epidemiological consequences (probability of introduction, increase and decrease, medical impact for human beings and pets) and the economical impact in case of animal kept for company or for animal husbandry income, as well as for all the community. On the contrary, ticks need wetter conditions. Thus, it is necessary to monitor populations of these anthropods and the periodicity of their biological cycles. The recent introduction of vectors and exotic virus in Europe may have determined a change of epidemiology and diffusion of diseases transmitted by arthropods even if their consequences are difficult to predict. Medical and economical consequences of environmental modifications, of the introduction of exotic vectors have been estimated for each disease. In addition, the diffusion in space and in time of numerous parasitic anthropod vectors of diseases is continuously changing as consequence of environmental modifications, of the introduction of exotic vectors, of climate changes and of the behaviours of society. This phenomenon will likely have a significant impact on health and on animal well being and, in certain cases, on public health. The control of these insects has been historically given to pesticides. On the other side, considerable concerns are linked to the use of pesticides, considering the fact that they may involve problems manage the problem of pathologies transmitted by them $(6 ; 7)$. Recent studies, besides have emphasized how the environmental interactions and climatic changes, may influence the evolutionary dynamics of Calicivirus in humans and animals. The type Vesivirus and Lagovirus include pathogen animal responsible of different patologies, such as gastroenteritis, vesicular lesions, respiratory infections, reproductive or hemorrhagic disease. Norovirus and Sapovirus infect mainly man, despite some animal pathogen have been included in these types. The ecology for Calcivirus is widely unexplored, but there are a lot of clues that suggest la possibility of transmission of virus among different animal species between animal and man. The presence at the same time of human enteric and animal calcivirus in food represents a conjunction ring extremely favourable to give rise, through infection/co-infection, to the appearance of new viruses thanks to mechanisms of recombination. The molecular study of calcivirus is important to understand the ecology of these viruses in the different animal species and in man (13). The environmental interactions and modifications connected with them are responsible for a series of pathologies due to conditioning processes and have a negative influence on the Immunitary System. It represents a bulwark for infections of different origin. Its capacity and competence are essential to protect from viral infections. It offers a wide range of answers to these pathogens aiming at eliminating the pathogen from the body and developing a specific memory capable to protect our body in amore efficient way. Pathologies are numerous and are divide into infectious, parasitic and not infectious. For years it has been a common knowledge that stress may modify the immunitary condition. Recently the mechanisms trough which stress, of social and psychological or physical-environmental type, modify the immunity have been studied. A series of researches on this topic has led to important interpretative hypothesis. In particular, it is stated the it is necessary to distinguish these following conditions: Stress due to physicalenvironmental conditions, and the consequent activation of the hormonal system and specifically of the hypophisis-adrenal axis. In this kind of stress it is involved the nervous system together with a specialised network of neuro-endocrine mediators and above all of catecholamine. The effects sometimes may be also salutary. Stress due to social and psychic conditions, and the consequent activation of the hypophisis adrenal cortical axis and glucocorticoid production and immunosuppressive effects. Acute stress during which mechanisms of reactions take place. Chronic stress during which there are phenomena of resistance (adaptation) and collapse (breakdown). In concrete situations the first two types of stress (physicalenvironmental and social and psychic) interweave. Between acute stress and chronic one, phases of transition exist and during chronic stress it is possible to have acute phases. In animals during stress conditions, there are complex activations and retroactions, which concern not only the hormonal system and the nervous one, both correlated and interdependent. One of the most emerging aspect for pathologies due to conditioning situations is that of Infectious Immune Circuits caused by stress. For instance, an animal infected by a latent infection of Herpes virus, a situation of stress may lead to the reactivation of the viral infection which causes an aggression to the Immunitary System together with the induction of immunosuppression. This, in turn, conditions a bacterial pathology, as for example a sepsis from Pasteurella or from another bacterium of which the animal was symptom-free carrier. Situations like these make a correct interpretation of a lot spontaneous pathological events, correlated to stress situations, difficult (19). The environmental interactions, the delicate mechanism of evolutionary dynamics of pathogen agents have been described as well as it has been touched on the role played by stress on the Immunitary System. These effects seem to be negative on health. This means that in a short period, the Health systems will have to adopt measures which allow an adequate adaptation. In a long period, health may protected only maintaining the integrity of 
ecosystems and in the prevention and control activities the draft of guide lines to minimize risks are necessary (20).

\section{Material and Method}

Tackling the above-described issues requires what can be termed an 'integrated-participatory' control. Integrated-Participatory Planning (IPP) is the most modern instrument available for planning and organizing human activities in urban areas: these are both urban and extra-urban (20).

\subsection{Integrated and participatory planning approach} Methodologies for health integrated plannings have to plan: risk analysis; innervations to control the environmental quality; applications of auto control systems; adhesion to programs of healthy cities; the implementation of Agenda 2030 processes for achievement the SDGs $(25 ; 17)$. Cities are true 'organisms' and as such they form part of a more complex system, the surrounding or catchment area. As organisms, cities can be studied from a methodological point of view in terms of their growth mechanisms, their transformation and their decline by making use of an innovative approach as a discipline. The principles of the development and growth of an ecosystem can be applied to planning, i.e., the principles can be applied to the establishment of a rational regional planning policy. Cities are high energy-consumption systems which impact on nature in order to maintain their balance. The aim of integrated-participatory planning is to understand and protect the natural environment which is so vital to the maintenance of life; to protect the quality of life in cities; to regulate - insofar as this is possible - the type and pace of development in order to ensure that it does not exceed the carrying capacity of nature and to ensure that pressures on the environment be kept to a minimum; to exploit nature less and more efficiently and to recycle more. An ecological understanding of an area means reestablishing and guaranteeing harmony between urban settlements and the surrounding extra-urban territory. Appropriate strategies must be chosen to combat environmental deterioration, by planning and applying rules governing human settlements both inside cities and outside them which will themselves generate a new and lasting environmental equilibrium (Figure 1) (20).

\subsection{Ecological Balance Sheets}

During the planning stages, it is necessary to assess all aspects of the interaction between the environmental and the effects of climate change on the evolution of pathogens in urban ecosystems; it is also necessary to identify the positive impact of using ecological balance sheets. Ecological balance sheets help enhance and improve feedback; this can be achieved by redefining management by means of an environmentally correct approach. Ecoplan methodologies use theme maps as cognitive instruments and guidance instruments; assessments are carried out and sustainable planning solutions are found (eco-management) (20). That is to say, sustainable plans are predicated upon a reduced ecological footprint as compared to the past. Using ecological criteria for both protection of the environment and planning can help in merging cities with the countryside by understanding appropriate urban sustainability indicators (application of Agenda 2030) such as the following: biodiversity zones and natural zones, it being understood that cities are structured like a mosaic of habitats; emergency indices and the ratio of use of renewable energy in cities; indices of the ratio of population (including animal population)/recycling/restoration; material recycling ratios and introduction of the ecological footprint parameter as an compulsory element to be used in city planning. These assessments pertain, above all, to the levels of vulnerability, to the level of critical state and to the potential of the ecosystem under study. At the end of this assessment stage, a sustainability matrix shall be established (cause/effect and the incidence levels); intervention plans shall be drafted, including proposals for changing the current technical management levels in urban settings.

\section{Results and discussion \\ 3.1 Urban Sustainability Indicators}

Integrated-participatory planning studies urban ecosystems; it is, therefore, an instrument to be used to gain a better understanding of the spaces and the functional cycles of cities (biotopes) and of the interaction among the living organisms living there (biocenosis). This is the context in which to adopt methodologies reconciling specific needs - which can be defined as 'global' needs with what can be termed 'local' needs in such a way as to draw up targeted action plans predicated upon that given reality. In this way, the 'Plan's' instruments become specialized operational instruments. Urban sustainability indicators can become very useful analytical and evaluative tools for the assessment of actions and strategies adopted in cities. The indicators can also be used as guidance tools to adjust sustainable city planning policies to foster quality of life, the biodiversity and the health of the environment. Useful tools for this job are an environmental atlas of the city, a mapping of city biotopes and biocenosis and the drafting of ecological balance sheets in order to gain a deeper understanding of the state of health of the environment and in order to draw up detailed and itemized plans such as for: infrastructure, housing, business zones, city fauna, city garden, public gardens and agricultural ecosystems. All of these plans can be read as ecosystems. Using an ecological balance sheet is of great benefit in understanding the state of health of the environment and in achieving a better grasp of the pressures of human activities on a specific area, not to mention its usefulness in terms of protecting the environment and in terms of helping the environment recover when responding to environmental, health and social 
problems in according with SDGs. Another useful tool is the indicators for sustainable development published recently by ASviS (1) with an online document entitled "Monitoring the SDGs at EU level with composite indicators". A unique set of composite indicators that summarize almost 70 elementary indicators, able to measuring progress and backward steps made by the 28 EU member states compared to the SDGs (2). For the first time at international level, a set of indicators summarizes the position of each of the $28 \mathrm{EU}$ member states in the perspecrive of the achievment of the UN Sustainable Development Goals. Given the complexity in verifying the implementation status of the 2030 Agenda, composite indicators are not intended to be a simplification of the problem, but a tool that allows a quick and concise view of the performance related to each Objective. The indicators were constructed using the Ampi methodology, also adopted by Istat for composite indicators of Fair and Sustainable Well-being (12).

The UN could soon launch a global environmental compact. A new, broader and more binding agreement, which will work in parallel with that of Paris and which must be able to restore environmental failures. During a meeting of the United Nations last September, the President of the General Assembly launched the idea of a Global Compact for the environment. A compact that could materialize after the UN has worked out about the most important environmental problems and failures (23). To address these issues, the Global Commission on the Economy and Climate, which aims to help governments, businesses and companies make more informed decisions on how to achieve economic prosperity and development, addressing the challenges of climate change, has developed the 2018 report "Accelerating climate action in urgent times" identifying five key economic systems: energy, city, food and land use, water and industry that are key sectors for the economy of the future. But the challenge is greater than we can imagine: the climate as a driver of social inclusion (24). In conclusion, the goal of this new growth approach is to ensure greater productivity, more resilient economies but above all social inclusion. The poor people are those most exposed to the impacts of global warming, and a new climate economy could not only benefit the environment, but also rebalance the injustices of our society (24). The consequent approach is of an efficient integration of operative structures which have to face problems, public services of prevention, Health Care, departments ISPRA; local authority.; research authority. The methodology has to be that of planning for objectives with planning, programming, execution and check of interventions with indicators of efficiency and efficacy which have not to regardless from the improvement of the inter professional collaboration between medical operators, doctors and vets and operators of the sector. One of the primary objective of the experts of urban ecology, urban hygiene, pest management is that to provide information that the political and administration community may use to control and manage environmental and health risks produced by an anthropic activity. One of the major difficulty in the application of these criteria consists in the overcoming of language barriers among disciplines so different. The expert has to learn to produce results that may be understood and properly used at different level. Objective evaluation criteria of the potential risks about health problems have to be analyse din general terms until to arrive to details. A major level of protection of public health is obtained considering the ancient logicity according to which when a pathology appears, the etiological and pathogenic aspects are privileged over those of public health. It is paid major attention to disease and overlook the general aspects which has determined the coming, different aspects should not be considered singularly, but integrate each other. The formulation of adequate criteria of indicators should be based on a set of data to which should be applied "factors of security" which allow the extrapolation of experimental values at a level considered protective for the environment and public health. The strategy proposed to face problems here described is that of a kind of control "Integrated - Partecipatory". The integrated and participatory planning is the newest instrument of planning tool and organisation of all human interventions on a mixed territorial area: Urban and extra urban. Basic element is the detailed analysis of territory of material and energy fluxes which cross it, in order to define the general renovation and reconversion of territory itself, under all the aspects: social, productive, infrastructural, housing and environmental, in an integrated and participated way $(20 ; 14)$. For "integrated" is meant that the control of a system is faced in its complexity, in order to consider a re-harmonization of all components respecting all the environmental and socio-cultural balance. For "participatory" is meant a planning which considers an intensive and active collaboration of social, productive strength of all citizens. The plan is not only the result of experts, but it develops with the full participation of citizens and it is subjected to testing, modifications rearrangements. Healthy Information has to be detailed and aiming at a complete divulgation on potential risks connected with climate changes, often connected with bad habits and lack of information. A strict collaboration between local health authorities and would be useful in prevention and control activities. An active and rapid preservation system which allows to find promptly epidemic hotbeds, is essential to monitor the potential risk linked to environmental interactions and climate changes. Thus, the objective has to be promote the preservation, valorisation a very good allocation of territorial resources, intended as single entities or as complex balance. The economic development has to be compatible with the charge capacity of the planet ecosystems and harmonic with the objectives of a democratic and fair society to achieve sustainable development goals (SDGs) by 2030. 
The protection of the cultural and historical identity, the preservation of the landscape quality, of its environmental components and its social and productive use, within the principle of a lasting development and less unsustainable are possible for a self-sustainable development (20). "It would seem a utopia but it is the only 'sustainable' possibility. The alternative would be a profound environmental, economic and social crisis of the whole world" (10). Each country must commit itself to defining its own sustainable development strategy that allows reaching the SDGs. This decade is crucial to putting humanity on a path of sustainable development. The change is necessary and this can happen with a strong commitment from all institutions and individuals, that is, from all of us. All of this must necessarily be accompanied by a lifestyle that respects sustainability and the Mediterranean way (22), is an example of how to combine personal choices, economic, social and cultural rights, protective of human health, biodiversity and the ecosystem.

\section{References}

1. AsviS. Monitoring the SDGs at EU level with composite indicators. ASviS Report 2018. Rome. Available online: http://asvis.it/public/asvis/files/ASVIS-REPORT-EU-COMPOS ITES-FINAL.pdf

2. AsviS.. Italy and the Sustainable Development Goals. ASviS $\begin{array}{llll}\text { Report } 2019 . & \text { Rome. Available online: }\end{array}$ https://asvis.it/rapporto-asvis-2019/

3. British Met Office. Decadal forecasts (bulletins), 2020. Available online: https://www.metoffice.gov.uk/research/climate/seasonal-to-dec adal/long-range/decadal-fc/index

4. Cafarchia, C., Romito, D., Iatta, R., Camarda, A., Montagna, M.T. \& Otranto, D. Role of birds of prey as carriers and spreaders of Cryptococcus neoformans and other zoonotic yeasts. Medical Mycology, 2006, 44 (6), 485-492.

5. Centers for Disease Control. One Health Office Fact Sheet; Connecting human, animal, and environmental health. Centers for Disease Control: Atlanta, GA, USA, 2020. Available online:

https://www.cdc.gov/onehealth/who-we-are/one-health-office-f act-sheet.html?CDC_AA_refVal=https $\% 3 \mathrm{~A} \% 2 \mathrm{~F} \% 2 \mathrm{Fwww} . \mathrm{cdc}$. gov\%2Fonehealth $\% 2$ Fmultimedia $\% 2$ Ffactsheet.html

6. Colwell, D.D., Dantas-Torres, F. \& Otranto, D. Vector-borne parasitic zoonoses: Emerging scenarios and new perspectives. Veterinary Parasitology, 2011, 182(1), 14-21.

7. Dantas-Torres, F., Figueredo, L.A. \& Otranto, D. Seasonal varation in the effect of climate on the biology of Rhipicephalus sanguineus in southern Europe. Parasitolology, 2011, 138(4), 527-536.

8. European centre for Medium Range Weather Forecasts (ECMWF). Climate bulletins. The Copernicus Climate Change Service of the European Union, 2020. Available online: https://climate.copernicus.eu/climate-bulletins

9. Gibbs, EPJ., Anderson TC. One World - One Health' and the global challenge of epidemic diseases of viral aetiology. Vet Ital., 2009, 45, 35-44.

10. Giovannini, E. L'Utopia Sostenibile, 2018, Laterza (Eds.), Rome.

11. Henrik Lerner \& Charlotte Berg. The concept of health in One Health and some practical implications for research and education: what is One Health? Infection Ecology \& Epidemiology, 2015, 5(1), DOI:10.3402/iee.v5.25300.
12. ISTAT. Bes report 2017. Istat, Rome. Available online: https://www4.istat.it/it/benessere-e-sostenibilit\%C3\%A0/misur e-del-benessere/il-rapporto-istat-sul-bes

13. Martella, V., Decaro, N., Lorusso, E., Radogna, A., Moschidou, P., Amorisco, F., Lucente, MS., Desario, C., Mari, V., Elia, G., Banyai, K., Carmichael, LE. \& Buonavoglia, C. Genetic heterogeneity and recombination in canine noroviruses. J. Virol. 2009, 83 (21), 11391-11396.

14. Nancy, B., Grove J. M., Pickett, S. T. A., \& Redman, C. L. Integrated approach to Long-Term studies of urban ecological systems. BioScience, 2000, 50, 571-584.

15. Puccini, V. \& Tarsitano, E. [Urban Parasitology: Cities, animals and public health]. In V. Puccini \& E. Tarsitano (Eds), [Introduction to Urban Parasitology] 2003, (pp. 1-13). Il Sole 24 ORE Edagricole, Bologna, Italy.

16. Ruhli, FJ.,Henneberg, M. New perspectives on evolutionary medicine: the relevance of microevolution for human health and disease. BMC Med; 2013, 11, 115.

17. SDSN. SDGs Index and Dashboard Report 2017. New York. Available online: http://unsdsn.org/resources/publications/sdg-index-and-dashboa rds-report-2017/

18. Tarsitano, E. [Urban Parasitology: Cities, animals and public health]. In V. Puccini \& E. Tarsitano (Eds), [Urban Ecosystem] 2003, (pp. 21-36). Il Sole 24 ORE Edagricole, Bologna, Italy.

19. Tarsitano, E. [Urban Parasitology: Cities, animals and public health]. In V. Puccini \& E. Tarsitano (Eds), [Management, prevention and integrated control of urban parassitosis] 2003, (pp. 331-341). Il Sole 24 ORE Edagricole, Bologna, Italy.

20. Tarsitano, E. Interaction between the environment and animals in urban settings: Integrated and Participatory Planning. Environmental Management, 2006, 38(5), 799-809.

21. Tarsitano, E. Effects of Climate Changes on the Spread of Pathogens: Risks to Biodiversity. International Journal of Sciences, 2013,10 (2): 56-62.

22. Tarsitano, E., Calvano, G., Cavalcanti, E. The Mediterranean Way a model to achieve the 2030 Agenda Sustainable Development Goals (SDGs), Journal of Sustainable Development, 2019, 12(1).

23. UN. Towards a Global Pact for the Environment. Resolution adopted by General Assembly on $10^{\text {th }}$ May 2018. New York. Retrieved from http://www.un.org/en/ga/search/view_doc.asp?symbol=A/RES/ $72 / 277$

24. UNCCD. Unlocking the Inclusive Growth Story of the 21st Century: Accelerating Climate Action in Urgent Times (Report) 2018. Global Commission on the Economy and Climate. Washington DC. Available online: https://newclimateeconomy.report/2018

25. United Nations Department of Economic and Social - Affairs (UNDESA)-Division for Sustainable Development Goals (DSDG). Transforming our World: The 2030 Agenda for Sustainable Development, 2015, (pp.1-41). United Nations. Available online: https://sustainabledevelopment.un.org/post2015/transformingou rworld

26. Woetzel, J., Pinner, SD., Samandari, H., Engel, H., Krishnan, M., Boland, B. and Powis C. Climate risk and response. Physical hazards and socioeconomic impacts (report) 2020, (pp.1-164). McKinsey Global Institute. Available online: https://www.mckinsey.com/ /media/McKinsey/Business\%20Fu nctions/Sustainability/Our\%20Insights/Climate\%20risk\%20and $\% 20$ response $\% 20$ Physical $\% 20$ hazards $\% 20$ and $\% 20$ socioecono mic\%20impacts/MGI-Climate-risk-and-response-Full-report-vF .ashx

27. World Health Organization. Coronavirus disease (COVID-2019) situation reports. World Health Organization (WHO), 2020. Available online: https://www.who.int/emergencies/diseases/novel-coronavirus-2 019/situation-reports 
Effects of Climate Changes on the Diffusion of Infectious and Parasitic Disease: Environmental and Socio-Economic Impacts

Figure 1. Schematic illustration of the Integrated-Participatory Planning (IPP) (Tarsitano, 2006)

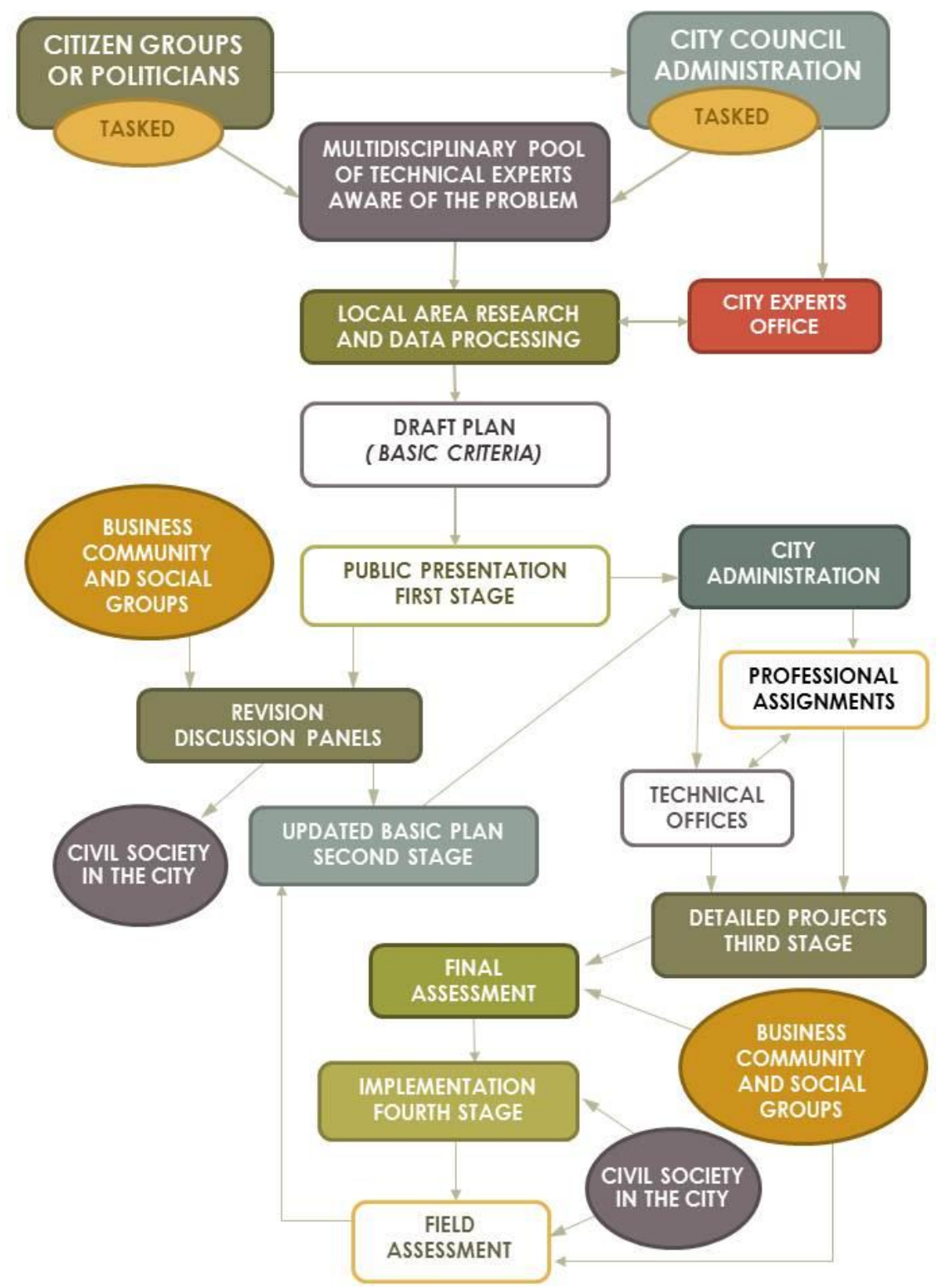

